\title{
BIBLIOGRAFIA
}

\section{Obras Críticas y Biográficas Referentes a la Novela Mexicana Anterior al Siglo XX ${ }^{(1)}$}

A fin de hacer más útil esta bibliografia se hallará adjunto un indice de los novelistas citados que se debe consultar. Me he referido a otras bibliografías para hacer ésta menos larga en contados casos, que son los de Ignacio M. Altamirano (véase núm. 352 abajo), Federico Gamboa (núms. 209 y 210) y Fernández de Lizardi (núm. 317). Sin embargo, hay que ver el índice para saber las adiciones que se han hecho a estas bibliografías. He omitido a Amado Nervo porque ya se han publicado varias bibliografías muy extensas de obris sobre él. Se dará a luz en otra parte una lista más completa de obras que tratan de Heriberto Frias y de Salvador Quevedo y Zubieta, quienes por la indole de sus novelas pertenecen más bien al siglo XX. A pesar de ser algo defectuosa, la mejor bibliografía de la novela mexicana es la de Torres-Rioseco (núm. 338), aunque todavía no se puede prescindir de la de Iguíniz (núm. 160) que contiene notas biográficas y críticas.

La ubicación de las obras citadas es como sigue:

BB Biblioteca Bancroft, Los Angeles, California.

BC Biblioteca del Congreso, Washington, D. C.

BI Biblioteca Iberoamericana, México, D. F.

BL Biblioteca Lincoln, México, D. F.

BN Biblioteca Nacional, México, D. F.

BPB Biblioteca Pública, Boston, Massachusetts.

BU Biblioteca de la Universidad de México.

CML Columbus Memorial Library, Washington, D. C.

COR Biblioteca de la Universidad de Cornell, Ithaca, Nueva York.

CU Biblioteca de la Universidad de Columbia, Nueva York, Nueva York.

EM Biblioteca del autor. 
NY Biblioteca Pública de Nueva York, Nueva York.

NYU Biblioteca de la Universidad de Nueva York, Nueva York. PR Biblioteca particular de Pedro Robredo, México, D. F.

SGE Biblioteca de la Sociedad de Geografía y Estadística, México, D. F.

UA Biblioteca de la Universidad de Arizona, Tucson, Arizona.

UC ... Biblioteca de la Universidad de California, Los Angeles, California.

UCA Biblioteca de la Universidad Católica de América, Washington, D. C.

UH Biblioteca de la Universidad de Harvard, Cambridge, Massachusetts.

UP Biblioteca de la Universidad de Pennsylvania, Philadelphia, Pennsylvania.

US Biblioteca de la Universidad de Stanford, Stanford, California.

UT Biblioteca de $\mathrm{l}_{2}$ Universidad de Texas, Austin, Texas.

UW Biblioteca de la Universidad de Washington, Seattle, Washington.

Y Biblioteca de la Universidad de Yale, New Haven, Connecticut.

1. Abreu Gómez, Ermmo, Clásicos, románticos, modernos.-México, Eds. Botas, 1934. 217-(2) pp. Apareció antes en la revista mericana Contemporáneos. (Sierra O'Reilly, Peón y Contreras, Sigüenza y Góngora) BC-BN-EM.

2. Agürros, Viçtoriano, Almanaque de "El Tiempo", diario católico de México.-México, Imp. de "El Tiempo", de Victoriano Agüeros y Ca., 1887. 148 pp. láms. (Flores Alatorre, Ramón Valle) BN.

3. - Artículos literarios.-México, Imp. de Ignacio Cumplido, 1880. 397-(3) pp. (La juventud literaria, pp. 173-184; Nuestra literatura, Pp. 185-202) BN-PR.

4. - Cartas literarias.-México, Imp. de La Colonia Española, 1887. 505-(1) pp. PR.

5. - Don Peón y Contreras.-El Nacional, III (1881), 40-53. BN.

6. - Escritores mexicanos contemporáneos.-México, Imp. de Ignacio Escalante, 1880. xii, 225 pp. retrs. (Roa Bárcena, Peón y Contreras) BN-PR.

7. - Luis G. Ortiz, Don José María Ramirez, Agapito Silva.El Nacional, IV (1882) BN.

8. - Obras literarias. I. Artículos sueltos.-México, Imp. de V. Agüeros, Edit., 1897. xxix, 483 pp. láms. Biblioteca de Autores 
Mexicanos, vol. 8. (Véanse pp. 161-180 y una noticia del autor) BI-BN-BU-Y-UC.

9. Agüeros de la Portilla, Agustín, El periodismo en México durante la dominación española... Anales del Museo Nacional de Arqueologia, Historia y Etnologia, II (1910), 357-465. láms. (Villaurrutia) NY-BN-UT-UC.

10. Album de la Paz y el Trabajo.-México, (Edit. Ireneo Paz, 1910). 359 pp. ilustr. (Bolaños Cacho, I. Paz) BN.

11. Alcaraz, Ramón I., Anastasio de Ochoa y Acuña.-El Liceo Mexicano, I (1844). BN-BC-Y-NY-BPB-BH.

12. Almanaque Bouret para el año de 1896.-Formado bajo la dirección de Carlos Roumagnac. México, Libr. de la Vda. de C. Bouret, s.a. 212 pp. (Gutiérrez Nájera, Peza, Chavero) BN.

13. Altamirano, Alberto I., Influence de la littérature française sur la littérature mexicaine; essai de littérature comparée.-México, Librairie Cosmos, (1935) (13)-111 pp. (Menciona a los autores principales) BC-BN-COR-EM.

14. Altamirano, Ignacio M., Fernando Orozco y Berra-El Renacimiento, I (1869), 129-131. UT-NY.

15. - Florencio María del Castillo.-Ibid., I, 500-502. UT-NY.

16. —_ Glorias nacionales.-México, 1862-1866. 11 fols. en $4^{8}$ (F. M. del Castillo, P. Tovar).

17. — La literatura en 1870.-El Federalista, 6 mar. 1871. BN$\mathrm{BC}-\mathrm{NY}$.

18. —_ La quinta velada literaria.-El Siglo Diez y Nueve, 6 feb. 1868. (Justo Sierra O'Reilly, Cuéllar) BN.

19. —— Revista de la semana.-Ibid., 7 enero 1868. (Olavarria, Ortiz) BN.

20. - Revista de la semana.-Ibid.; 19 junio 1870. (Riva Palacio, Olavarría) BN.

21. —, Revista de la semana.-Ibid., 21 ago. 1870. (Cuéllar) BN.

22. —_- Revista literaria y bibliográfica.-Historia bicnal de la Repriblica Mexicana, editada por Manuel Caballero, pp. 75-89. México-Nueva York, Charles M. Green Printing Co., (1883).

23. - Revistas literarias de México, por Ignacio M. Altamirano.México, T. F. Neve, Imp., 1868. 203 pp. BC-EM.

24. — Revistas literarias de México.-Edición de "La Iberia". México, F. Díaz de León y S. White, 1868. 202-(1) pp. (Payno, A. Chavero, Zayas, Riva Palacio, Rodríguez Galván, Mateos, Cuéllar, Frías y Soto, J. M. Ramírez, Lizardi, Pizarro, Rivera, P. Tovar, F. M. del Castillo, Díaz Covarrubias, Orozco y Berra y algunos novelistas de la generación del '68) BC-Y.

25. Alzate y Ramírez, José Antonio. La vida de la muerte de Fray de Bolaños.-Gazeta de Literatura de México, III, 3, 4, 5 (30 nov. 
22 dic. 1792; 8 enero 1793), 15-34. NY-Y-UT-BC. Hay una segunda edición de este periódico de 1831 . BB-BC.

26. Allemand, P. F., Rafael Delgado, costumbrista mexicano.-Tesis de maestro, Universidad de Texas Austin, Texas, 1930. UT.

27. - Rafael Delgado, costumbrista mexicano.-Anales del Museo de Arqueología, Etnología e Historia, época cuarta, VII, 1 (1931), 147-236. BN-NY-UC.

28. AmÉzaga, Carlos G., Poetas mexicanos-Buenos Aires, Imp. de Pablo E. Coni e hijos, 1896. 414 pp. (Carpio, Riva Palacio, Peón y Contreras, Roa Bárcena, Ortiz, Sosa, Sierra, Diaz Covarrubias, Rosas Moreno, Gutiérrez Nájera, Othón, López Portillo y Rojas, Peza, Porfirio Parra) BN.

29. ANdRade, Vicente de Paúl, Necrología (Villaseñor y Villaseñor) por...-Boletin de la Sociedad de Geografia y Estadistica de la Repriblica Mexicana, $5^{7}$ época, vol. V. UC-UT-NY.

30. $\longrightarrow$, Seudónimos de autores. - El Tiempo, 16 abr. 1904. BCCML.

31. Arjona, Doris King, y Vázquez Arjona, C., Beginnings of nationalism in the Mexican novel.-Revue Hispanique, LXXXI, 440455. NY-UC-UT.

32. Arróniz, Marcos. Manual de biografía mejicana. . . París, Libr. de Rosa, Bouret y Cía., 1857. viii, 317-(3) pp. Enciclopedia Popular Mejicana. (Carpio, Ochoa y Acuña, Rodríguez Galván, Pesado) BB-BC-BN-HS-PR-Y.

33. AvILA, PaBlo, The introduction of romanticism into Mexican literature.-Tesis de doctorado, Universidad de Stanford. Stanford, California, 1937, 2 vols. 756 pp.

34. Avir.a Escalante, Alvaro, Contribución al estudio de la bistoria de la medicina en Yucatán.-Leído en las sesiones del Comité en Mérida de la Asociación Médica Mexicana los días 12 de marzo y 15 de octubre de 1925. Mérida, Yucatán, Imp. y Rayado Universal, 1926. (10)-101 pp. retrs. (Peón y Contreras) BN.

35. Ayala Duarte, Crispín, Ensayo critico y antológico de la bistoria de la literatura bispanoamericana. México y Centroamérica.-Caracas, Ed. Americana, 1935. 138 pp.

36. - Historia de la literatura mexicana.-Anales de la Universidad Central de Venezuela (Caracas), enero-jun. 1932, pp. 124-56; enero-jun. 1933, pp. 195-217. CML-UC-Y-BC-CU.

37. Bancroft, H. H., Essays and miscellany.-San Francisco, California, The History Co., 1890 . vi, 764 pp. Véase el cap. XVII. COR-BB-BC. Vol. 38 de sus Obras. COR-BB.

38. Barrera, IsaAc J., Historia de la literatura bispanoamericana.-Quito, Imp. de la Universidad Central, 1934. 459-(2) pp. (Altamirano, Sierra) EM-BC.

39. Basave, Agustín, Algo sobre la novela mexicana y Carlos González Peña.-Revista Azul, VII (1920), 45-50. 
40. Beristán y Souza, José Mariano DE, Biblioteca bispanoamericana septëntrional o catálogo y noticia de los literatos, que o nacidos o educados, o florecientes en la América Septentrional española, ban dado a huz algiin escrito, o lo ban dexado preparado para la prensa. México, Oficina de D. Alejandro Valdés, 1\$16-1821. 3 vols. NYBC.

41. - Idem.-Segunda edición. Publícala el Presbitero Br. Fortino Hipólito Vera. Amecameca, Tip. del Colegio Católico, 1883. 3 vols. NY-BC-UC.

42. — Idem.-Tomo IV. Comprende los anónimos que dejó escritos el autor, las adiciones del Dr. Osores y otras añadidas posteriormente por las personas que se expresan. José Toribio Medina publicalo ahora con una introducción biobibliográfica. Santiago de Chile, Imp. Elzeviriana, 1897. liii, 199 pp. Véase abajo núm. 268. BC-UC.

43. Biblioteca de autores mexicanos. 78 vols.-México, V. Agüeros, 'último editor. Véanse los prefacios en esta valiosa colección de textos. BU.

44. Biblos.-Boletín semanal de información bibliográfica, publicado por la Biblioteca Nacional, 1919-1922. 4 vols. ilustr. (Vol. I: Genaro García, I. Paz, Quevedo y Zubieta, López Portillo y Rojas, H. Frías, Sosa; II: Rubín, Martínez Gracida, V. F. Frias, Ross; III: Vigil y Robles, Pavia, Ramírez Cabañas, Guadalajara, Bolaños Cacho; IV: Olaguibel) BN-NY-BC-UT-US-UA.

45. BicKiey, JAmes G., The life and works of Rafael Delgado.-Tesis de doctorado, Universidad de California. Berkeley, California, 1935.

46. Caballero, Andrés de, Justo Sierra y el francesismo.-Letras de México, II, 16 (15 abr. 1940), 5. EM.

47. Caballero, Manuel, Almanaque mexicano (segundo).-México, Imp. y Lit. de la Oficina Impresora de Estampillas, 1896. (Revista literaria, pp. 23-32, por Amado Nervo) PR.

48. - Primer almanaque bistórico, artistico y monumental de la Repriblica Mexicana.-México-Nueva York, The Chas. M. Green Printing Co., Imp., 1883. vi, 377-(6) pp. (Revista literaria y bibliográfica, pp. 75-89) BB-BC-PR.

49. CAmpo, ANGel DE, Recuerdos del maestro.-Cosas vistas. .. por Micrós, pp. 215-225. Motelia, Mich., Imp. y Enc. "Garibaldi", 1905. 236-(2) pp. (Altamirano) BU-EM.

50. Campos, RuBÉn M., El folklore literario de México...-México, Pubs. de la Sec. de Educación Pública, Talleres Gráficos de la Nación, 1929. 690-(6) pp. (R. Valle, Lizardi, Rosas Moreno, Othón) EM-BC.

51. Carpio, Manuex (Juan de Linza), Hombres de letras, Lic. D. José López-Portillo y Rojas.-La Crónica (Guadalajara), I, 5 (1 mar. 1907), 55-56. BN. 
52. Carreño, Alberto María, Don José López-Portillo y Rojas como novelista.-Revista de Revistas, XIV, 681 (1923), 50; 682, 4849. BC-NY-UT.

53. —— El Lic. José López Portillo y Rojas.-México, Imp. Victoria, 1923. SGE.

54. Carreño, Franco, Novela corta y noveladores en México-Biblos, segunda época, I, II, núms. 1, 2, 3 (mayo-jul. 1925). BN-NY-BCUT-US-UA.

55. Carrillo y Ancona, Crescencio, Yucatecos célebres, Don Justo Sierra.-El Repertorio Pintoresco (Mérida, 1861), pp. 496-502. UT.

56. Casasús, Joaquín D., En bonor de los muertos...-México, Imp. de Ignacio Escalante, 1911-1913. 2 vols. I, 254-(4) pp. (Chavero, Peón y Contreras, Sierra) BB-BC-BI-NY.

57. Castañeda, Alfonso M., Los regionalismos de "La Parcela" del Lic.

- D. José López Portillo y Rojas. Investigaciones Literarias, IV, 1-2, (enero-abr. 1937), 63-69. COR.

58. Castañeda, C. E., Algunos escritores contemporáneos de México. Hispania (Stanford, California), VII (1924), 177-181. COR.

59. Castillo Ledón, Luis, La novela mexicana.-El Diario, 28 oct. 1907.

60. - Idem.-Crónica (Guadalajara), I, 22 (15 nov. 1907), 35860. BN.

61. - Orígenes de la novela en México.-Anales del Museo $\mathrm{Na}$ cional de Arqueologia, Historia y Etnologia, cuarta época, I (mayo-jun. 1922), 203-8. NY-PR-Y-UC-U'T.

62. $\longrightarrow$ Idem.-México, Imp. del Museo Nacional, 1922. 15 pp. PR.

63. Cejador y Frauca, Julio, Historia de la lengula y literatura castellana.-Madrid, Tip. de la "Revista de Archivos, Bibliotecas y Museos", 1915-1922. Véanse tt. 6-12. BC-COR.

64. Claretre, Jules, Art et littérature-Le Mexique au début du xxe. siècle, vol. II, 223-266. París, Librairie:Ch. Delagrave, (1904). 2 vols. NY.

65. - Idem.-Traducido. Biblos, IV, 178-195 (1922). BC-BNNY-UT-US-UA.

66. CoESTER, ALFRED, An anthology of the modernist movement in Spanish America.-Boston, Nueva York, Ginn and Co., 1924. xxxvii, 314 pp. (Gutiérrez Nájera).

67. —_- Historia literaria de la América española.-Madrid, Hernando, 1929. xii, 564 pp. BC.

68. - The literary bistory of Spanish America-Dueva York, The Macmillan Co., 1916. xii, 495 pp. BC-UC:

69. - Idem.-Second edition. Nueva York, The Macmillan Co., 1928. xiii, 522-(2) pp. Cap. XI et passim. : BC-EM. 
70. - La literatura mexicana-Biblos, IV (1922). Cap. traducido de la citada historia literaria. BN-NY-BC-UT-US-UA.

71. Cooley, Irene, Social aspects of the Periquillo Sarniento.-Tesis de maestra, Universidad de W ashington. Seattle, Washington, 1935.

72. Códero, Salvador, La literatura durante la guerra de Independercia.-México-París, Libr. de la Vda. de Ch. Bouret, 1920. 43 pp. (Lizardi) BC.

73. CoRnyn, John H., Cuentos mejicanos.-Richmond, Va., Johnson Pub. Co., 1925. xxiv, 219 pp. Véase el prefacio. BC-EM.

74. —_, Living literary men of Mexico.-México, s.p.i., 1916.

75. - Mexican literature-Modern Mexico, XVI (mar. 1904), 32-33. (Siruación literaria) BC-CML-NY.

76. - Mexico. Literature-Encyclopedia of Latin America, editado por M. Wilcox y G. E. Rines, pp. 465-471. Nueva York, The Encyclopedia Americana Corp., 1917. COR-UC-BB.

77. Couto, JosÉ Bernardo, Biografia del Señor Doctor Don Manuel Carpio.-Boletín de la Sociedad de Geografia y Estadistica de la Repriblica Mexicana, VIII. BN-UC-UT-NY.

78. - Biografía de don Manuel Carpio.-Memorias de la Academia Mexicana, I. BN.

79. Cruzado, Manuel, Bibliografía juridica mexicana--México, Tip. de la Oficina Imp. de Estampillas, 1905. (4) -385 pp. (Sierra O'Reilly, Ruiz) BN-BC-UC.

80. - Memoria para la bibliografía jurídica mexicana.-México, Antigua Imp. de E. Murguia, 1894. 139 pp. (Sierra O'Reilly) BN-BC.

81. Cú́llar, José T. DE, La literatura nacional.-El Artista, III (1875), 209-213. NY.

82. - La literatura nacional.-El Renacimiento, II (1869), 186189. UT-NY.

83. Chavero, Alfredo, Obras. Escritos diversos-México, Tip. de Victoriano Agüeros, Edit.; 1904. xxv, 464 pp. lám. Biblioteca de Autores Mexicanos, vol. 51. (Biografía del autor por Nicolás León) BN.

84. - Tovar por..-Anales del Museo Nacional de México, segunda época, I (1903). láms. UC-UT-NY.

85. Chávez, Ezequiel A., Altanitano inédito y su novela inconclusa "Atenea"--México, Imp. Universitaria, 1935. 26-(2) pp. EM.

86. Danielson, Gertrude, Social aspects of Mexico in the novels of Francisca Betanzo.-Tesis de maestra, Universidad de Minnesota. Minneapolis, Minn., 1937. is pp.

87. Dávila Y Arrillaga, Mariano, Breves observaciones sobre la novela titulada Monja y casada, virgen y mártir...-Opúsculo publicado en la Revista Universal. México, Imp. Literaria, 1869. 121 pp. PR. 
88. Diccionario enciclopédico bispano-americano de literatura, ciencias y artes. . - Barcelona, Montaner y Simón, eds., 1887-1910. 28 vols. (Varios novelistas) COR-BC-UC.

89. Diccionario universal de bistoria y de geografia...-México, Tip. de Rafael, Libr. de Andrade, 1853-1856. 10 vols. Véanse el t. II y los 3 últimos tt. BB-BN-HS.

90. Diez civiles notables de la bistoria patria.-México, Sec. de Instrucción Pública y Bellas Artes, 1914. 184-(3) pp. retrs. (Justo Sierra, pp. 173-184, por Laura Méndez de Cuenca) BC-BN-NY.

91. Dominguez, Ricardo, Galeria de escritores y periodistas de la "Prensa Asociada".-México, Imp. de "El Partido Liberal", 1890. 103 pp. (I. Paz, Gutiérrzz Nájera, Ríos, Bravo) BC-BN.

92. - Los poetas mexicanos. Semblanzas breves.-México, Imp. de Pedro J. García, 1888. 93, ii pp. (Peza, Gutiérrez Nájera, Silva, Zayas Enriquez, Esteva, Castera, Rodriguez Rivera, F. J. Jens, P. Parra, Delgado) BC-BN.

93. Downrng, T., Calvario y tabor, by V.. Riva Palacio--Books Abroad (Norman, Oklahoma), V (1931), 267.

94. DzierzykraJ-Morawoski, JóseF, Literatura biszpanska, Literatura biszpansko-amerik., Literatura portugalska, pp. 1157-8. Varsovia, Nakadem Trzaski, Everta I. Michalskiego, s.3. (1935). (Lizardi, Payno, Inclán, Cuéllar, P. Parra, Delgado) EM.

95. Elguero, Francisco, director, América Española.-Revista quincenal destinada al estudio de los intereses más importantes de la patria mejicana y de la raza española... México, 1921-1922. 2 vols. (López-Portillo y Rojas) BN-UCA-NY.

96. Elguero, José, Política contemporánea. Los mexicanos en el destierro, por Antimaco Sax (seud.) San Antonio, Texas, International Print. Co., 1916. 179-(2) pp. (Rabasa) BN.

97. Escandón, Luis A., Poetas y escritores mexicanos. Primera edición.México, Imp., Lit. y Encuad. de Ireneo Paz, 1889. 127 pp: (Ireneo Paz, Esteva, A. Paz, Iza, Silva, Sosa) BN-BC.

98. Estrada, Genaro, Poetas nuevos de México. Antología con noticias biográficas, criticas y bibliográficas.-México, Eds. Porrúa, Tip. de José Ballescá, 1916. xiii, 338 pp. (Gutiérrez Nájera, Othön, Sierra) BN-BC-UC.

99. Figueroa, Pedro Parlo, Pensadores americanos....-Santiago de Chile, Imp. de "El Correo", 1890. 137 pp. (Sosa, Ramírez) BCHS-NY.

100. — Un poeta indígena.-Santiago de Chile, Imp. B. Vicuña Mackenna, 1893. 56 pp. (Altamirano) COR.

101. Fineau, Isaeelle $\mathrm{K}$, Vicente Riva Palacio, a study of bis life and bis bistorical novels.-Tesis de maestra, Universidad de Texas. Austin, Texas, 1931. 88 pp. más bibliografía. 
102. FurNess, EDNa, The literary theories of José López-Portillo y Rojas.-Tesis de maestra, Universidad de Colorado. Boulder, Colorado, 1940.

103. Gaumdo, Miguel, Apuntes para la bistoria de la literatura mexicana.-Colima, Imp. El Dragón, 1925. 313-(3) pp. BC-PR-Y.

104. Galindo Y Villa, Jesús, Algunos Gregorianos ilustres.-Boletín Oficial del Consejo Superior de Gobierno del Distrito Federal, XVI (1910). (Cuéllar, Riva Palacio) BN.

105. - El Panteón de San Fernando y el futuro Panteón Nacional.-Anales del Museo Nacional, segunda época, IV (1907), 337-552. (Olaguíbel) BN-NY-UC-UT.

106. —— El Presbitero D. José Antonio Alzate y Ramírez ... - México, Imp. del Gobierno en el ex-Arzobispado, 1890. (Bolaños, pp. 16-17) BC-NY.

107. Gallo, Eduardo L., edit., Hombres ilustres mexicanos. Biografias dé los personajes notables desde antes de la conquista basta nuestros días.-México, Imp. de I. Cumplido, 1873-1874. 4 vols. (Anastasio de Ochoa y Acuña, por Francisco de A. Lerdo en el t. III, 151-157) BB-BC-BN-HS-NY.

108. Gamboa, Federico, Mi diatio.-México y Guadalajara, 1918-1938. 5 vols. (Campo, Delgado, López Portillo y Rojas, Rabasa, Lizardi, Payno y otros) BC-BN-EM-UC-Y.

109. - La novela mexicana.-Conferencia leída en la "Libreria" General", el día 3 de enero de 1914. México, Eusebio Gómez de la Puente, editor, 1914. 27 pp. retr. (Novelistas principales) BC-EM-PR-Y.

110. - Idem.-Revista de Derecho, Historia y Letras (Buenos Aires), XVII, 51 (mayo 1915), 56-59 y (jun. 1915), 254-266. CML.

111. GÁmEZ, LUis E., Justo Sierra: bistoriador, educador y literato.Tesis de maestro, Universidad de Texas. Austin, Texas, 1939.

112. Garcia Cubas, Antonio, Diccionatio geográfico, bistórico y biográfico de los Estados Unidos Mexicanos.-México, Antigua Imp. de Murguia, 1888-1891. 5 vols. Véase núm. 309 y los novelistas citados. BB-BC-BN-NY.

113. ——, El libro de mis recuerdos. Narraciones bistóricas, anecdóticas y de costumbres. . - México, Imp. de Arturo García Cubas Hnos, 1904. 635 pp. Véase nútm. 309 abajo y los novelistas citados. BB-BC.

114. - - Idem. Segunda edición.-México, Imp. de Manuel León Sánchez, 1934. 639 pp. BC-BN.

115. Gaxiola, Franctsco Javier, Gobernantes del Estado de México. Múzquiz-Zavala-Olaguibel.-Toluca, Oficina Tip. del Gobierno en la Escuela de Artes y Oficios, 1899. cvi pp. (Olaguíbel) BN. 
116. - Revistas literarias sobre escritores sinaloenses. . -México, Imp.; Lit. y Enc. de Ireneo Paz, 1890. v, 91-(1) pp. lám. Biblioteca de la Revista de México. (A. Paz, José Ferrel) BN.

117. Godoy, Bernabé, Corrientes culturales que definen al Periquillo.Guadalajara, México, Navegación Poética, 1938. 73-(3) pp. EM.

118. Godox, JosÉ F., Enciclopedia biográfica de contemporáneos.Washington, D. C., Establecimiento Tip. de Thos. W. Cadick, 1898. 322 pp. ilustr. (Chavero, Olavarria, P. Parra, I. Paz, Peza, Ruiz, Sierra, Zárate) BB-BC-UC.

119. - Quién es quién en la ciudad de México y Distrito Federal. Directorio comercial Murguía y guía de la ciudad de México, 1925-1926, pp. 1067-1164. (Ceballos, Pavía, Quevedo y Zubieta, Ramírez Cabañas, Ross) BN-BC.

120. González, Silvano M., edit., Fichas bio-bibliográficas mexicanas. Dos series. (Rabasa, Rodríguez Galván) EM.

121. González Obregón, Luis, Biografía de D. Ignacio M. Altamirano.-Boletin de la Sociedad Mexicana de Geografía y Estadistica, serie $4^{*}$, II, 724-743. BN-UC-UT-NY.

122. — Idem.-México, Sociedad Mexicana de Geografía y Estadística, 1893. 24 Pp. SGE.

123. — La bola, por E. Rabasa.-El Liceo Mexicano, II (1886), 173-. UT-NY.

124. - Breve noticia de los novelistas mexicanos en el siglo XIX. México, Tip. de O. R. Spíndola y Cía., 1889. 63 pp. NY-PR-Y.

125. - Idem.-El Liceo Mexicano, II (1886), 54-56, 73-77. NY-UT.

126. — Don Justo Sierra, bistoriador. Panegírico-México, s.p.i., 1907. 37 PP. PR.

127. — Idem. Ensayos bistóricos y biográficos.-México, Eds. Botas, 1937. 254-(2) pp. BN.

128. - José Joaquín Fernández de Lizardi (El Pensador Mexicano)...-México, Oficina Tip. de la Sec. de Fomento, 1888. xii, 91 pp. BB-BC-PR-Y.

129. —— Idem. Segunda edición.-México, Eds. Botas, 1938. 223(4) pp. BI-EM-SGE-Y.

130. - La literatura nacional-El Liceo Mexicano, I (1885), 41-45. UT-NY.

131. _ Luis G. Inclán en la novela mexicana. Novelistas predecesores y contemporáneos.-El Universal, 3 enero 1932. (Altamirano).

132. - Noticia biográfica. Ignacio M. Altamirano. Rimas.-México, V. Agüeros, 1899. pp. v-xxviii. BN-BU-UC.

133. —, La novela en México-El Liceo Mexicano, II (1886), 2022. NY-UT. 
134. - Prefacio de El bombre de la sitzación, por Manuel Payno. México, Eds. León Sánchez, 1929. EM.

135. González Peña, Carlos, Las bodas de oro de un novelista. Letras de México, II, 10 (oct. 1939), 6. EM.

136. - Historia de la literatura mexicana, desde los orígenes has-

ta nuestros dias.-México, Pubs. de la Sec. de Educación Pública, 1928. 550 pp. BC-BN-EM.

137. —— Idem. Segunda edición corregida y aumentada.-México, Edit. Cultura y Polis, 1940. 327-(3) pp. EM.

138. - L Luis G. Inclán en la novela mexicana.-México, Edit. Cultura, 1931. 40 pp. más 8 de contestación por V. Salado Alvarez. BU.

139. - El Pensador Mexicano y su tiempo. Conferencias del Ateneo de la Juventud.-México, Imp. Lacaud, 1910. 166-(2) pp. Véanse las pp. 87-108. EM.

140. González Ramírez, Manued, Altamirano. Biografias popnlares.México, Eds. de la Universidad Nacional, 1936. 23-(1) pp. EM.

141. Grace, Delfina G., Heriberto Frías y la novela nacional.-Tesis de maestra, Universidad de Texas. Austin, Texas, 1939.

142. GRAY, Katherine B., Traditional lore and customs in Fernández de Lizardi's El Periquillo Sarniento.-Tesis de maestra, Universidad de Columbia. Nueva York, 1937. 268 pp. incluyendo una bibliografía.

143. Griffith, Verona T., The short story in Mexico.-Tesis de maestra, Universidad de Texas. Austin, Texas, 1937. 79 pp.

144. Grismer, R. L., El Zarco. Episodios de la vida mexicana en 1861 1863 por I. M. Altamirano.-Edited with notes and vocabulary. Ilustr. by X. Martínez Suárez. Nueva York, Norton, 1933. xix, 205 pp. port. ilustr. mapas, bibliografía, pp. vxiii-xix. BC.

145. Guadalupe Romero, José, José Joaquín Pesado.-Boletín de la Sociedad de Geografía y Estadistica de la Repriblica Mexicana, XI (1864). BN-UC-UT-NY.

146. Hall, E. F., Mexican fiction 1816-1920.-Tesis de maestro, Universidad de George Washington. Washington, D. C., 1927.

147. Hammond, JoHN H., The prose works of Don José María Roa Bárcena.-Tesis de maestro, Universidad de Texas. Austin, Texas, 1935.

148. Harper, P., I. M. Altamirano, poet and novelist.-Tesis de maestro, Universidad de Washington. St. Louis, Missouri, 1931. 58 pp.

149. HaWLEY, A. C., Mexican life and customs as seen in the novels of Rafael Delgado.-Tesis de maestro, Universidad de Columbia, 1932.

150. Hazard, Paur, Traductions populaires des romantiques français au Mexique.-Revue de Littérature Comparée (París), $\mathrm{X}$ (1930), 148-159. COR.

151. Henriquez Ureñs, MAX, El retorno de los galeones. Bocetos bis- 
pánicos-Madrid, Renacimiento, (1930). 259 pp. (Influencias europeas) BC-EM.

152. Hernández, Carlos, Mujeres célebres de México.-San Antonio Texas, Casa Edit. Lozano, 1918. 183-(3) pp. retrs. (Barragán de Toscano) BB-BC-BN-NY.

153. Holmes, Henry A., Spanish America in Song and story, selections...-Nueva York, Henry Holt and Co., 1932. xxxi, 578 pp. (Sierra, Delgado, Lizardi) BC-EM.

154. Hollingshead, Laura A., Mexican life as depicted in the novels of José Ĺópez-Portillo y Rojas.-Tesis de maestra. Universidad de Washington. St. Louis, Missouri, 1931.

155. Hollingsworth, R. L., J. Peón y Contreras and the romantic movement in Mexico.-Tesis de doctor en filosofia, Universidad de Virginia. Charlottesville, Virginia, 1933: Se publicó un resumen en University of Virginia Abstracts of Dissertations, 19321933, pp. 16-17. COR.

156. Homenaje a Ignacio M. Altamirano. Conferencias, estudios y bibliografía.-México, Imp. Universitaria, 1935. viii, 211 pp. (Contiene: Biografía de I. M. Altamirano, L. González Obregón; Altamirano orador, Rubén $\mathrm{M}$. Campos; El mexicanismo en la poesía de Altamirano, José de Jesús Nứñez y Domínguez; Altamirano, novelista, C. González Peña; ... demócrata, Salzador Azuela; ... poetá, E. González Martínez; Actividad política de ...., Juan Sánchez Azcona; ... inédito, Ezequiel A. Chávez; Bibliografía, R. H. Valle) BN.

157. HoRNer, BRITA L., El carácter mexicano revelado por su literatura.Tesis de maestra, Universidad de México. México, Pub. de la Sec. de Educación Pública, 1922. BU.

158. Horta, Aurelio, Mexicanos ilustres. Bosquejos biográficos para el uso de los establecimientos de instrucción pública. México, Imp. del "Hijo del Trabajo", 1883. - 123-(5) pp. (Carpio, Rodríguez Galván). „BB-BN-PR-NY.

159. Howatr, Glonia, José T. de Cuéllar.-La Nueva Democracia (Nueva York), ago. 1939.

160. Iguíniz, JuaN B., Bibliografia de novelistas mexicanos. Ensayo biográfico, bibliográfico y crítico precedido de un estudio bistórico de la novela mexicana por Francisco Monterde García Icazbalceta. México, Imp. de la Sec. de Relaciōnes Exteriores, 1926. xxxv, 433 pp. Monografías Bibliográficas, núm. 2. BN-BC-EM.

161. - Biografía de Eduardo Ruiz.-Boletín de la Biblioteca Ibero Americana y de Bellas Artes, I, 4-6 (mar.-mayo 1939), 23. EM.

162. - Catálogo de seudónimos, anagramas e iniciales de escritores mexicanos...-París-México, Libr. de la Vda, de Ch. Bouret, 1913. 62 pp. BC-BN.

163. Sinónimos y anagramas de escritores mexicanos.-Biblos, I, 40 (29 nov. 1919). NY-BN-BC-UT-US-UA. 
164. Janvier, T. A., Legends' of the City of Mexico. Nueva : YorkLondon, Harper and Bros., 1910. xvii, 165 pp. (Riva Palacio, Peza) BC.

165. Jiménez Rueda, Julio, Antología de la prosa en México.-México, Pubs. de la Universidad Nacional, 1931. 305 pp. Véanse las notas críticas. BC-EM.

166. —— Idem. Segunda edición corregida y aumentada. México, Eds. Botas, 1935 . 506 pp. (Lizardi, Payno, Roa Bárcena, Cuéllar, Altamirano, Riva Palacio, Sierra, Delgado, Gutiérrez Nájera, Campo, Rabasa) BC-BN.

167. —- Historia de la literatura mexicana.-México, Ed. Cultura, 1928. 296 pp. BC.

168. - Idem. Segunda edición puesta al día y aumentada con buen número de notas bibliográficas. México, Eds. Botas, 1934. 323 pp. BC-EM.

169. —— Reszimenes de literatura mexicana, (segunda edición).México, Linotipografía H. Barrales, Sucr., 1922. 32 pp. BCEM.

170. Jones, Mary M., The literary art of Yucatan-Tesis de maestra, Universidad de Southern California. Los Angeles, California, 1933. (Los Sierra).

171. KAHLe, Luis G., Life and works of Manuel Payno.-Tesis de maestro, Universidad de Texas. Austin, Texas, 1937. 107 incluso bibliografía, pp. 99-107.

172. KaUfMaN, JACLYN, El romanticismo en la literatura mexicana.Tesis de maestra, Universidad Nacional Autónoma, Escuela de Verano. México, D. F., 1936. 94-(2) pp. BL.

173. Lacayo, H., Costumbres mexicanas expresadas en "El Periquillo Sarniento" de J. J. Fernández de Lizardi.-Tesis de maestro, Universidad de Southern California. Los Angeles, California, 1930.

174. LanUza, Agustín, Historia del Colegio del Estado de Guanaxuato. -México, M. León Sánchez, Imp., 1924. 433 pp. láms. (Rosas Moreno, R. Valle) BN-BC.

175. Lanz, Manuel, A., Bosquejo biográfico del Dr. Justo Sierra de O'Reilly.-Campeche, Imp. del Gobierno del Estado, 1906. 30 pp. NY.

176. - Idem.-Revista Moderna, mayo 1906, pp. 135-147. UT.

177. Lara, MargartTa Olrvo, Biografías de veracruzanos distinguidos. -México, Imp. del Museo Nacional de Arqueología, Historia y Etnografía, 1931. 468 pp. 56 retrs. BN.

178. Laughun, Mabel S., Purposeful activities of Ignacio M. Altamirano.-Tesis de maestra, Universidad de Southern California. Los Angeles, California, 1934. 107 pp., incluye una bibliografía.

179. Leduc, Alberto, et al., Diccionario de Geografia, bistoria y biografía mexicana-París-México, Libr. de la Vda. de C. Bouret, 1910. viii-1109 pp. (Cuéllar y otros muchos) BC-CU-NY. 
180. León, Nicolás, Ex-libris de bibliófilos mexicanos.-Anales del Museo Nacional, época tercera, V (1913), 65-124. (Chavero, V. F. Frías, G. Garcia, Olaguíbel, Riva Palacio) BN-UC-UT-NY.

181. - Hombres ilustres y escritores micboacanos. Galería fotográfica y apuntamientos biográficos.-Morelia, Imp. del Gobierno, a cargo de José R. Bravo, 1884. viii, 104 pp. (Silva) BN-BC.

182. — La obstetricia en México. Notas bibliográficas, étnicas, bistóricas, documentarias y criticas de los orígenes bistóricos basta el año de 1910.-México, Tip. de la Vda. de F. Díaz de León, Sucs., 1910. viii, 743-(4) pp. ilustŗ. (Demetrio Mejía) BNBC-UC.

183. Leonard, Irving, A. ... Don Carlos de Sigüienza y Góngora. Berkeley, California, Pubs. of the University of California, 1929. Univ. of Calif. Publication in History, núm. 18, x, 287 pp. BCUC.

184. - Ensayo bibliográfico de Don Carlos de Sigüenza y Góngora.-México, Monografías Bibliográficas Mexicanas, núm. 15, 1929. $\mathrm{x}, 65$ pp. BC-COR.

185. López y López, Manuel, Modismos y refranes del Periquillo Sarniento.-Universidad de México, I, 6, 462-482. COR.

186. López-Portillo Y Rojas, JosÉ, Elogio de Manuel José Othón.Memorias de la Academia Mexicana, VI (1910).

187. - La novela, breve ensayo presentado a la Academia Mexicana. México, Tip. Vizcaíno y Viamonte, 1906. 62 pp. BNPR-UT.

188. - Idem--Memorias de la Academia Mexicana, VI (1910), 49-103.

189. López-Pontillo y Rojas; Rafael Delgado.-El Imparcial (Guadalajara), I, 313 (16 jun. 1892), 3. BN.

190. LutRexl, Estelle, Mexican writers, a catalogue of books in the University of Arizona Library.-Tucson, Arizona, Pub. by the University of Arizona, 1920. 83 pp. BB-CU-NY-UC.

191. Maclean, Malcolm Dallas, El contenido literario de "El Siglo Diez y Nucve".-Tesis de maestro de artes, Escuela de Verano, Universidad Nacional de México. México, Imp. Mundial, 1938. 78 pp. BL-BC.

192. Madero, Francisco I., La sucesión presidencial en 1910...-San Pedro, Coahuila, Diciembre de 1908. 357 pp. (Frías, pp. 185187) BC-EM.

193. Magdaleno, Mauricio, ed., Angel de Campo, Pueblo y canto.Prólogo y selección de... México, Edición de la Universidad Nacional Autónama, 1939. Biblioteca del Estudiante, núm. 9. xxii, 210 pp. Véase el prólogo.

194. - El sentido de lo mexicano en "Micrós".-El Libro y el Pueblo, XI, 11 (1933), 404-410. CML-NY-UC-UH-UT-Y. 
195. Mafrler, T., The life and work of Angel de Campo-Tesis de maestro, Universidad de Texas. Austin, Texas, 1933. 71 pp. más 7 de bibliog. más un apéndice de 5 poemas.

196. MaIllefert, Alfredo, Micrós.-Universidad de México, V, 25 (feb. 1938), 42, BC-COR.

197. Manseid, I. M., I. M. Altamirano.-Tesis de maestro, Universidad de Texas. Austin, Texas, 1928. 81 pp. más 6 de bibliog.

198. Martínez Alomía, Gustavo, Historiadores de Yucatán.-Apuntes biográficos y bibliográficos de los historiadores de esta Peninsula desde su descubrimiento hasta fines del siglo XIX. Campeche, Tip. "El Fénix", 1906. xii, 360 pp. (Palma y Palma, Pavía, Villaseñor y Villaseñor). BB-BC-BN-UC.

199. MCLENNAN, ELFREDA M., The social background of the novels of Federico Gamboa.-Tesis de maestra, Universidad de Washington. Seattle; Washington, 193-. $58 \mathrm{pp}$.

200. Medina, José T., La imprenta en México (1939-1821). Santiago de Chile, Impreso en casa del autor, 1907-1912. 8 vols. BBBC-NY.

201. Meléndez, Concha, Novela indianista en Hispanoamérica (1832. 1889).-Madrid, Hernando, 1934. 199 pp. BC-CU.

202. Menéndez, C. R., El Dr. don Justo Sierra O'Reilly.-Mérida, Yucatán, Cía. Tip. Yucateca, 1939. 30 pp. EM.

203. Menéndez y Pelayo, Marcelino, Historia de la poesía hispanoamericana.-Madrid, Libr. General de Victoriano Suárez, 19111913. 2 vols. Obras Completas, tt. 2 y 3. (Ochoa y Acuña, Rodríguez Galván, Carpio, Pesado, Rosas Moreno) BN-COR-NY.

204. Mérimée, ERnest, Compendio de bistoria de la literatura espanola.-Trad. de Francisco Gamoneda. México, Eds. Botas, 1931. xix, 433 pp. (Apéndice sobre literatura mexicana) BN-BC.

205. MoNTERDE, FRANCISco, Introducción a la Bibliografía de novelistas mexicanos, México, 1926. xxxy pp. Véase núm. 160 arriba. (Los novelistas principales).

206. - Idem. El Consultor Bibliográfico.-(Madrid), I, 7 (feb. 1926), 110-125. NY.

207. - Idem.-México, s.p.i., 1926. 29 pp.

208. - Juan Diaz Covartubias.-Biblos, I, 15 (26 abr. 1919), 12. BC-BN-UT-NY-US-UA.

209. Moore, Ernest R., Bibliografia de Federico Gamboa (1864-1939). Letras de México, II, 12 (15 dic. 1939), 11; 13 (16 enero 1940), 7. EM.

210. Bibliografía de obras y crítica de Federico Gamboa (18641939).-Revista Iberoamericana, II, 3, abr. 1940), 271-279, (más completa).

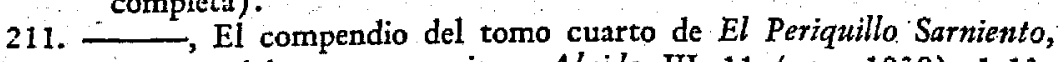
ensayo crítico y manuscrito.-Abside, III, 11 (nov. 1939), 1-13; 12 (dic. 1939), 1-30. EM. 
212. Moreno Cora, Srlvestre, La crítica literaria en México. Memorias de la Academia Mexicana; VI (1910), 135-181.

213. - Obras.-México, Imp. de V. Agüeros, 1901. xxiii, 591 pp. retrs. Biblioteca de Autores Mexicanos, vol. 32. (Carpio; $L a$ calandria de Rafael Delgado, pp. 393-427) BC-BU.

214. Murphy, ABIGaIL, French intervention as reflected in a few representative bistorical novels.-Tesis de maestra, Oklahoma Agricultural and Mechanical College. Stillwater, Oklahoma, 1937.

215. NeIson, Mary, The Mexican historical novel.-Tesis de maestra, Universidad de Texas. Austin, Texas, 1927. 102 pp. más 12 de bibliog.

216. Nichols, G., The period of French Intervention as treated in the Mexican novel.-Tesis de maestro, Universidad de Arizona. Tucson, Arizona, 1922.

217. NoRveIl, A. S., Romanticism in Spanish-American literature.Tesis de maestro, Universidad de Washington. St. Louis, Missouri, 1931.

218. NÚÑEZ Y DomíngueZ, José de Jesús, El novelista Inclán. Los poetas jóvenes de México y otros estudios literarios.-París-México, Libr. de la Vda. de C. Eouret, 1918. 153-(1) pp. (Pp. 6988; Lizardi) BC-BI-EM-Y.

219. Olavarría y Ferrari, EnRtQue DE, El arte literatio en México, noticias biográficas y criticas de sics más notables escritores...Málaga, España, Imp. de la "Revista de Andalucía", (1877).

220. _- Idem. Segunda edición.-Madrid, Espinosa. y Bautista, (1878). 224-(4) pp. (Valioso, véase cap. III) BN-EM.

221. - Poesías líricas mejicanas de Isabel Prieto, Rosas, Sierra, Altamirano, Flores, Riva Palacio, Prieto y otros autores, coleccionadas y anotadas. Segunda edición.-Madrid, Dirección y Administración Calle de Leganitos, 18, 1882. 190-(2) pp. Biblioteca Universal, vol. 45. (Los citados y Peza, Peón Contreras, Gómez Vergara, Zárate, Gallardo, Silva, Ortiz, Anselmo Alfaro) BN.

222. - La Sociedad Mexicana de Geografía y Estadistica.-México, Oficina Tip. de la Sec. de Fomento, 1901. (4)-183 pp. BC-SGE.

223. ONís, Federico DE, Antología de la pocsia española e bispanoamericana (1882-1932).-Madrid, Pubs. de la "Revista de Filología Española", 1934. (Gutiérrez Nájera, Othón) BC.

224. Ormand, I., Mexico's new poets.-Bookman (Nueva York), XIIX (1919), 101-106. (Gutiérrez Nájera, Othón) NY.

225. ORTIZ de Monteliano, Bernardo, Antologia de cuentos mexicanos.-Selección y prólogo de... Madrid, Edit. "Saturnino Calleja", 1926. 290 pp. BC-NYU.

226. Ortiz Vidales, Salvador, Tres bandidos mexicanos.-Véase El Movimiento Histórico en México, núm. 3 (mayo-jun. 1940), 2. (El Zarco) EM. 
227. Osores Sotomayor, Félix, Historia de todos los colegios de la cindad de México desde la conquista basta 1780. México, Talleres Gráficos de la Nación, 1929. xii, 215 pp. Nuevos Documentos Inéditos o Muy Raros para la Historia de México, vol. 2. BC.

228. - Noticias bio-bibliográficas de alumnos distingutidos del Colegio de San Pedro, San Pablo y San Ildefonso de México.-México, Vda. de C. Bouret, 1908. 2 vols. Documentos Inéditos o Muy Raros para la Historia de México, vols. 8 y 21 . BB-BC.

229. OursLer, L., Rafael Delgado, regional novelist of Mexico.-Tesis de maestro, Oklahoma Agricultural and Mechanical College. Stillwater, Oklahoma, 1927.

230. Oviedo y Romero, Aurelto María, Biografías de mexicanos célebres. París-México, Libr. de Ch. Bouret, 1889. 7 vols: ilustr. Biblioteca de la Juventud. (Anastasio Ochoa, t. 5) BN.

231. Oviedo Vinlegas, Jesús J., Un siglo de la novela mejicana.-Tesis de maestro, Universidad Nacional Autónoma. México, D. F., 1934. 137-(3) pp. BL-BN.

232. Palaviciní, FÉLIX F., Los diputados.-México, Tip. "El Faro", s. 2. 590 pp. (Olaguíbel) BN-BC.

233. —_ Idem. Segunda edición.-México, Imp. Francesa, 19151916. 2 vols. (Idem.) $\mathrm{BN}-\mathrm{BB}$.

234. Pavía, Lázaro, Apuntes biográficos de los miembros más distinguidos del Poder Judicial de la República Mexicana.-Tomo I. México, Tip. y Lit. de F. Barroso, Hermano y Co., 1893. \$10, ii pp. retrs. (E. Ancona, Ruiz, A. Paz) BN.

235. Paz, Ireneo, Los bombres prominentes de México...-México, Imp. y Lit. de "La Patria", 1898. 488, ii pp. retrs. (Cuéllar, Chavero, Mateos, P. Parra, Payno, J. M. Ramírez, Riva Palacio, Rodríguez Rivera, Ruiz, Sosa) BB-BC-CU-US.

236. - México actual. Galería de contemporáneos.-México, Tip. de "La Patria", 1898. 428 pp. retrs. (Arriaga, Martínez Gracida, Pavía, Sánchez Mármol, Zárate) BC-BN.

237. Pellicer, CÉsar, Biografía de Manuel Sánchez Mármol-Boletín de la Biblioteca Ibero Americana y de Bellos Artes, I, 4-6 (mar.mayo 1939), 43-47. EM.

238. PeÑa, Rafael ANGel DE LA, Angelina, estudio crítico.-Renacimiento, $2^{3}$ época, I (1894), 129-32, 145-148. UT-NY.

239. - Idem. Obras de D. Rafael Angel de la Peña.-México, V. Agüeros, 1900. xix, 478 pp.' Biblioteca de Autores Mexicanos, vol: 30 . BC-UC.

240. Idem. Memorias de la Academia Mexicana, IV (1895), 119-137.

241. Peña y Reyes, Antonio de la, Facundo, colaborador de El Renacimiento.-El Renacimiento, III (1894), 97-98. UT-NY.

242. $\longrightarrow$, Muertos y vivos.-México, Imp. de la Calle de Jesús, núm. 6, 1896. 95 pp. (Cuéllar, Ortiz, Gutiérrez Nájera) BN. 
243. - Vidas y tiempos; diccionario biográfico mexicano...- - $\mathrm{Ha}$ bana, Imp. "El Renacimiento", 1915. El único vol. publicado incluye las letras A-D. BC-NY.

244. Pérez, Ricardo, Efemérides nacionales o narración anecdótica de los asuntos más culminantes de la bistoria de México.-México, Tip. y Enc. "La Idea del Siglo", 1904. 455 pp. (Rosas Moreno) BN-BC-BB.

245. Pérez Martínez, Héctor, Facundo en su laberinto-El Libro y el Pueblo, XII, 3 (1934), 115-122. Incluye una bibliog. NYUC-Y-CML-UH-UT.

246. — Piraterias en Campecbe...-México, Porrúa Hnos. y Cía., 1937. 84 pp. (Sierra O'Reilly).

247. Pírez Salazar, Francisco, Biografía del Lic. D. Pascual Almazán.-Memorias de la Sociedad Científica "Antonio Alzate", XLII.

248. - D. Ignacio Rodríguez Galyán.-El Museo Mexicano, II (1843). UT-Y-CML-UP.

249. Pesado, JosÉ JoAquín, Littérature mexicaine-Revue des Races Latines (París), II (1857), 668-677. UH-UCA-NY.

250. PezA, JuAN de Dios, De la gaveta intima. Memorias, reliquias y retratos.-París-México, Libr. de" la Vda. de Ch. Bouret, 1900. iv, 410 pp. (Olavarría, Sosa) BN-Y.

251. - Poetas y escritores modernos mexicanos,-México, s.p.i. (al fin: "México, Diciembre 31 de 1877"). 95 pp. PR.

252. - Idem. El anuario mexicano, 1877.-México, Filomeno Mata, 1878. Véanse Pp. 147-239. (Altamirano, López-Portillo y Rojas y otros) BN.

253. - Idem. Nueva Revista de Buenos Aires, VIII (1883), 550579; IX, 124-144, 448-471, 598-618.

254. Pimentel, Francisco, Histotia crítica de la poesía en México. Obras completas.-México, 1903-1904. vols. 4 y 5. (A. M. Ochoa, Carpio, Orozco y Berra, Díaz Covarrubias, P. Tovar, GaIlardo, Pesado, Rodríguez Galván, Rosas Moreno, P. J. Villasenor) $\mathrm{BN}$.

255. - Historia crítica de la literatura mexicana, cap. XV. El Nacional (1881), II, 22-31, PR.

256. — Idem, cap. VII. Ibid., II, 72-86. PR.

257. - Novelistas y oradores mexicanos.-Obras completas, $\mathrm{V}$, 257-508. México, 1903-1904. (Bramón, Piña Izquierdo, Gonzálcz Sánchez, J. Villaurrutia, Orozco y Berra, Díaz Covarrubias, Sicrra O'Reilly, Castillo, P. Tovar) BC-BN-PR-NY.

258. Prieto, Guillerino, Memorias de mis tiempos, 1840 a 1853.-Pa-

rís-México, Libt. de la Vda. de Ch. Bouret, 1906. I, 380 pp. II, 447 pp. BB-BC-BN-Y-EM.

259. Provini, A. M., An interpretation of the rustic poetry of M. J. 
Othón.-Tesis de maestro, Universidad de Pittsburgh. Pittsburgh, Pennsylvania, 1937.

260. Quijano, Alejandro. El verdadero Ateneo.-Letras de México, 19. (15 nov. 1937), 2. EM.

261. QuIroz, ALBerto, Situación de la literatuta mexicana.-León, Gto., Eds. Guanajuato (1933). 62-(1) pp. (Rabasa, Riva Palacio, Campo, López-Portillo) BC-EM-Y.

262. Radin, Paul, Annotated bibliograpby of the poems and pamphlets of J. J. Fernandez de Lizardi. The first period (1808-1819).San Francisco, California, Calif. State Library Publication, 1940. 80 hojas. EM-BC.

263. —- Idem. The second period. Ibid., 179 pp. EM-BC.

264. - The opponents and friends of Lizardi. San Francisco, California, Calif. State Library Publication, 1939. 134 hojas. EM-BC.

265. - Some newly discovered poems and pamphlets of J. J. Fernández de Lizardi (El Pensador Mexicano). San Francisco, California, Calif. State Library Publication, 1938. 78 hojas. EMBC.

266. Ramírez, Ignacio. Estudios sobre literatura. El Renacimiento, I, 56-58. UT-NY.

267. — Idem. Obras.-T. I. México, Oficina Tip. de la Sec. de Fomento, 1889. BC-Y.

268. Ramírez, José Fernando, Biblioteca Hispano Americana Septentrional. Adiciones y correcciones que a su fallecimiento dejó manuscritas y son las que cita con el nombre de "Suplemento" o "Adición" en las apostillas que puso a su ejemplar de la Biblioteca Hispano-Americana del Dr. D. J. Mariano de Beristain y Souza. Publícanlas por vez primera el Lic. Victoriano Agüeros y el Dr. N. León. México, Imp. de El Tiempo, 1898. xlxii, 663 pp. Biblioteca de Autores Mexicanos, vols. 15 y 16 . BN-Y-BCUC.

269. Ramírez Cabañas, Joaquín.-Altamirano y el barón de Wagner. Estudios bistóricos, pp. 149-175. México, Eds. Botas, 1935. 175(3) pp. BC-BN.

270. - Don Rafael Delgado.-Nosotros, 241.

271. —_ El Pensador Mexicano.-Estudios históricos, pp. 7-26. Véase núm. 269 arriba.

272. READ, J. LloYd, The Mexican bistorical novel, 1826-1910.-Nueva York, Instituto de las Españas, 1939. 337-(9) pp. (Jicoténcal, El misterioso, Sierra O'Reilly, Payno, Díaz Covarrubias, E. Ancona, Altamirano, Olavarría y Ferrari, Riva Palacio, J. Mateos, P. Almazán, I. Paz, D. Mejía, M. de Castro, H. Frías) BC-CUEM.

273. Revnla, Manuei G., El historiador y novelistz Don José M. Roa 
Bárcena._Memorias de la Academia Mexicana, VI (1910), 263287.

274. Reyns, Alfonso, Justo Sierra y México-Letras de México, II, 17 (15 mayo 1940), 1-2. EM.

275. Ríos, ALfonso M. DE Los, et al. Liberales ilustres mexicanos de la Reforma y la Intervención...-México, Imp. del "Hijo del Ahuizote", 1890. 440-(2) pp. láms. (F. M. del Castillo, por Luis González Obregón) BN.

276. (Riva Palacio, Vicente), Los ceros. Galería de contemporáneos, por Cero (seud.)-México, Imp. de F. Díaz de León, Edit., 1882. 370-(1) pp. retrs. (Payno, Sierra, Chavero, Mateos, Sosa, Peza, Peón Contreras, Roa Bárcena) BB-BN-EM-NY.

277. —- Parnaso mexicano. Ignacio M. Altamirano; sul retrato $y$ biografía con el juicio critico de sus obras y poesías escogidas de varios autores, coleccionados bajo la dirección del Sr. Gral...México, La Ilustración, 1885 . 96 pp. NY.

278. Roa Bárcena, José María, Obras. Biografías.-México, Imp. de 'V. Agüeros, Edit., 1902. 429-(3) pp. Biblioteca de Autores Mexicanos, vol. 41. (Pesado, Carpio) BN-UC.

279. Rodríguez PeN̂A, Ramón, Don Justo Sierra.-Boletín de la Sociedad de Geografia y Estadistica de la Repuiblica Mexicana, 5? época, V. UC-UT-NY-BN.

280. RojAs DE ZÚNIGA, CIEMENTINA, Estudio monográfico acerca de "La Quijotita y su prima" de don José Joaquín Fernández de Lizardi.-Tesis de maestra en letras, Universidad Nacional Autónoma de México, Facultad de Filosofía y Letras, 1936. 58-(8) pp. mimeo. BU.

281. Romero Manuel María y Silva, Gerardo M. Discursos en memoria de Juan Díaz Covarrubias.-El Federalista, II (1872). BC-NY.

282. Romero de Terreros, M. Y Rosenberg, S. L. M., Tradiciones y leyendas by V. Riva Palacio and Juan de D. Peza.-Nueva York, T. Nelson, 1927. xvi, 172 pp. BC.

283. Rosales, Hernán, la niñez de personalidades mexicanas.-México, (Impreso en los Talleres Gráficos de la Nación), 1934. 149(3) pp. retr. (Riva Palacio, Díaz Covarrubias, Sierra O’Reilly) PR.

284. Rosenberg, S. L. M., A brief anthology of Mexican prose...Stanford University, California, Stanford University Press, 1928. xxxv, 210 pp. En colaboración con E. H. Templin. (Delgado, perspectiva) BC-EM.

285., El naturalismo en México y don Federico Gamboa.-Bulletin Hispanique (Francia), XXXVI (1934), 478-.

286. $\longrightarrow$ La prosa mexicana. - Hispania (Stanford, California), XIII (feb. 1930), 7-19. 
287. Ruiz, Rodolfo B., Del lirico vergel potosino. Semblanzas y pergenios.-San Luis Potosi, Talleres Tip. de la Escuela Industrial Militar "Benito Juárez", 1919. 212 pp. lám. (R. del Castillo, Othón) BN.

288. Salado Alvarez, Victoriano, $D e$ mi cosecha, estzudios de crítica. Guadalajara, México, Imp. de Ancira y Hno. A. Ochoa, 1899. xiv, 106-(2) pp. (Delgado, Díaz Dufóo, Ceballos, Gamboa, Ló, pez-Portillo y Rojas, Olaguíbel) BU-BN-Y-EM.

289. — Máscaras, D. Rafael Delgado.-Revista Moderna, núm. 16 (ago. 1903), 241-243. UT.

290. - Prefacio de La guerra de tres años de Emilio Ráabasa, pp. 7-14.-México, Edit. Cultura, 1931. EM.

- 291. Salas i Medina, Jorge de, Ensayos de crítica literaria.-México, Imp. Mundial, 1934. 144 pp. BU.

292. —_ Jalapa $\mathrm{i}$ sus hombres de letras.-Abside, III, 1 (1939), 46-56. (A. Esteva, Zárate, Roa Bárcena) EM.

293. Salmans, Edith. La vida mexicana reflejada en las novelas de costumbres de México.-Tesis de maestra, Universidad de Southern California. Los Angeles, California, 1928. 108 pp. (Delgado y otros).

294. SÁNChEz, Luis AlberTo, Historia de la literatura americana.Santiago de Chile, Eds. Ercilla, 1937. 681 pp. EM-BC.

295. Sánchez Mármor, Manuel, Elogio del señor académico Don José Peón y Contreras.-Memorias de la Academia Mexicana, iVI (1910):

296. - Las letras patrias. Monografias.-México, Establecimiento de. J. Ballescá y Ca., Suc., 1902. 190-(4) pp. PR.

297. - Idem. Mexico: its social evolution.-Trad. por G. Sentiñón. México, J. Ballescá and Co., 1900. Sección VII del t. II. Hay también un original y una traducción francesa. COR.

298. Santacilia, Pedro, Del movimiento literario en México.-México, Imp. del Gobierno, 1868. iv, 128 pp. BB-BC-BN-EM.

299. Santaelta, Eliseo... Biografías de hombres ilustres. . -México, Talleres Gráficos de la Nación, 1930. 113-(2) pp. BC.

300. Segunda Conferencia Pan-Americana. Crónica social.-México, $F$. Laso y Cía., Imps, 1901. 379 pp. .ilustr. (Chavero, Sánchez Mármol) BN.

301. Serrano, Pedro, El General. Silueta del general Vicente Riva Palacio...-México, Eds. Botas, 1934. 188 pp. CU.

302. - Hispanistas mexicanos. Volumen I.-México, (Imp. N2cional), 1920. xiv, 130-(1) pp. (López-Portillo, Gamboa) BBBC-BN-EM.

303. Seymour, Arthur R., The Mexican "novela de costumbres".Hispania (Stanford, Calif.), VIII, 5 (nov. 1925), 283-289. 
304. Sirva, Gerardo M., Glorias nacionales.-México, Imp. del "Socialista" de M. López y Ca., Juan de Mata Rivera, Imp., 1879. 32 pp. NY.

305. SMItH, Virginia K., Appreciation of Hitgo in Mexico.-Tesis de maestra, Universidad de Texas. Austin, Texas, 1939.

306. Sosa, Francisco, Anuario biográfico nacional.-México, Imp. de "La Libertad", 1884. (923) pp. (Orozco y Berra, Díaz Covarrubias, Castillo, Gallardo, Reynel Hernández, Olaguíbel, Peón y Contreras, Pesado, Rodríguez Galván, Rosas Moreno, Sierra O'Reilly, Tovar, A. Ochoa y Acuña, Carpio) BN.

307. — Apuntamientos biográficos del Sr. Lic. D. Manuel Sánchez Mármol. . - México, Imp. Internacional, 1912. 30 pp. BC-Y.

308. - Biografía del ciudadano Licenciado General Vicente Riva Palacio, escritos por Francisco Sosa y M. Sánchez Mármol.-Mérida, Yucatán, M. Mimenza, 1873. 28 pp. Y.

309. - Biografía de mexicanos distinguidos.-México, Oficina de la Sec. de Fomento, 1884. xii, 1115-(8) pp. (Carpio, Pesado, Castillo, Díaz Covarrubias, Gallardo, A. Ochoa y Acuña, Olaguíbel, Orożco y Berra, Othón, Roa Bárcena, Rodríguez Galván, Rosas, Reynel Hernández, Sierra O'Reilly, Tovar) BB-BC-BNCU-BI-HS-NY-UC.

310. - Los contemporáneos. Datos para la biografía de algunos mexicanos distinguidos en las ciencias, en las letras $y$ en las artes. T. I.-México, Imp. de Gonzalo A. Esteva, 1884. xl, 386(6) pp. (J. M. Ramírez, Díaz Covarrubias, Cuéllar, Silva, Peón y Contreras, Sierra, Chavero, Ortiz) BB-BN.

311. ——, Los contemporáneos. El Nacional, VII (1883), 6 et passim.

312. - E - E femérides bistóricas y biográficas...-Edición de "El Nacional". México, Imp. de G. A. Esteva, 1883. 2 vols. (Algunas biografías aparecieron antes en El Nacional) I, $501 \mathrm{pp}$. BC-UC-Y-BN.

313. - Mantual de biografía yucateca. Mérida, Imp. de J. D. Espinosa e Hijos, 1866. xii, 228-(4) pp. (Sierra O’Reilly) BBBC-BN-CU-PR-Y.

314. SotomaỸor, JosÉ Francisco, Historia del Apostólico Colegió de Nuestra Señora de Guadalupe de Zacatecas. ..-Edit. Lic. Rafael Ceniceros y Villarreal. Segunda edición corregida y aumentada por el autor. Zacatecas, Imp. de "La Rosa" a cargo de M. Ceniceros, 1889. 2 fols. (Bolaños, J.) BC.

315. Speir, JefFerson R., The costumbrista movement in Mexico.Publications of the Modern Language Association, L, 290-315. Se publicó también traducido por Juana Manrique de Lara en Universidad de México, V, 27 (mar. 1938), 21-26. 
316. - The educational views of Fernández de Lizardi, Hispania (Stanford, California), IX (1926), 258-274.

317. - Fernández de Lizardi. A bibliography.-Hispanic American Historical Review (Durham, North Carolina), VII, 4 (1927), 490-507.

318. —— Fernández de Lizardi and his critics.-Hispania, XI (1928), $233-45$.

319. - - Fernández de Lizardi as a pamphleteer-Wispanic American Historical Review, VII (1927), 104-123.

320. — Fernández de. Lizardi: The Mexican Feijóo-_Hispania, IX (1926), 338-348.

321. - The genesis of the first Mexican novel--Hispania, XIV (feb. 1931), 53-58.

322. —_ Juan Díaz Covarrubias: a Mexican romantic.-Ibid., XV (oct. 1932), 327-344. También apareció en El Libro y el Pueblo, XI, 355-370. NY-UC-Y-CML-UH-UT.

323. - The life and works of José Joaquin Fernández de Lizardi.-Philadelphia, Pennsylvania, University of Pennsylvania Press, 1931. 141 pp. Publication of the Series in Romanic Languages and Literatures, $\mathrm{N}^{9} 23$. BC-CU-UT.

324. - The literary work of Manuel Payno.-Hispania, XII (oct. 1929), 357-366.

325. - Mexican periodicals in the nineteenth century.-PMLA (véase núm. 315), LII (mar. 1937), 272-312.

326. - Mexican society as seen by Fernández de Lizardi.-Hispania, VIII (1925), 145-165.

327. - Roussean in the Spanish world before 1833...-Austin, Texas, The University of Texas Press, 1938.325 pp. BC-UT.

328. STAPLEs, R. E., Fernández de Lizardi's theories on the education of the boy.-Tesis de maestro, Universidad de Pittsburgh. Pittsburgh, Pennsylvania, 1934.

329. STARr, FREDERICK, Readings from modern Mexican authors, Chicago, The Open Court Pub. Co., 1904. vii, 420 pp. retrs. (Chavero, Sosa, Villaseñor y Villaseñor, Peón y Contreras, Roa Bárcena, Sierra, I. Paz, López-Portillo, Sánchez Mármol, P. Parra, Rabasa, R. Delgado) BC-NY-UC.

330. Taylor, Mary E., José T. de Cuéllar.-Tesis de maestro, Universidad de Texas. Austin, Texas, 1935. 82 pp. más 4 de bibliog.

331. Terxidor, Felme, Bibliografía yucateca...-Mérida, Yucatán, México, Talleres Gráficos del Sureste, 1937. (Sierra O'Reilly) BC-EM.

332. - Ex-libris y bibliotecas de México. Monografias Bibliográficas Mexicanas, núm. 20.-México, 1931. xxxv, 550 pp. (Riva Palacio, Couto, Castillo, Chavero, V. F. Frías, G. García, Garcia Cubas, Olaguíbel, Ramirez Cabañas, P. Almazán, P. J. Villaseñor) BC.COR. 
333. El Tiempo. Edición literaria.-México, Imp. de la Biblioteca religiosa, histórica, científica y literaria, 1883. (Artículos por el director, V. Aguieros, sobre A. M. Ochoa, Rodríguez Galván, Pesado, Othón) UT-EM.

334. Tiscareño, ANGel de los Dolores. Nuestra Señota del Refugio Patrona de las misiones del Colegio Apostólico de Nuestra Señora de Guadalupe de Zacatecas.-Zacatecas, Talleres Nazario Espinosa, 1909. xi, 558 pp. ilustr. (J. F. Sotomayor) BN.

335. Torres, Mariano de Jesús. Parnaso micboacano...-Edición de "El Centinela".-Morelia, Imp. particular del autor, 1905. 480 pp. (Jesús Echáiz, Silva) BN.

336. Torres Caicedo, José María, Ensayos biográficos y de crítica literaria...-París, Guillaumin y' Cía., 1863-1868, 3 vols. (T. II: Rodríguez Galván, Pesado) BC.

337. Torres-Rioseco, Arturo, Antología de la literatura hispanoamericana, selección, comentarios, notas y vocabulario de...-Nueva York, Crofts, 1939. xiii, 225 pp. (Lizardi) BC-EM.

338. - Bibliografía de la novela mejicana-Cambridge, Massachusetts, Harvard University Press, 1933. viii, $58 \mathrm{pp}$. (Aunque faltan unas doscientas ediciones de novelas mexicanas, la mejor bibliog. todavía publicada). BC-UC-EM.

339. - Mexican short stories.-Nueva York, Prentice-Hall, 1932. $\mathrm{xx}, 180$ pp. (Véase la introducción) BC-EM. (En colaboración con E. R. Sims).

340. - La novela en la América Hispana.-Berkeley, California, University of California Press, 1939. 159-255 pp. Publications in Modern Philology, vol. 21, $\mathrm{N}^{\circ}$ 2, University of California. BC-EM.

341. Townsend, Tarlaton B., Federico Gamboa, bis life and works.Tesis de maestro, Universidad de Oklahoma. Norman, Oklahoma, 1935. 46 pp.

342. Turrell; Chas. A., Crítica: La navidad en las montañas, por 1. M. Altamirano.-Hispania (Stanford, California), I, 262.

343. UhINK Y FaRías, Valentín. Pláticas bibliográficas y literarias.El Artista, II, 51-58; III, 120-25. NY.

344. Urbina, Luis G., Hombres y libros.-México, El Libro Francés, s.a. 298-(1) pp. ilustr. (Sierra, Gutiérrez Nájera, Peza, Othón, Peón Contreras) BN-EM.

345. - La literatura mexicana-Conferencia leida en la "Librería General", el día 22 de noviembre de 1913. México, Imp. "La Pluma-Fuente", 1913, 12 pp. (Perspectiva) 12 pp. BN.

346. - La literatura mexicana durante la guerra de la Independencia,-Madrid, (Imp. de M. García y G. Sáez), 1917. 282(3) pp. BC-UC-COR-Y. Reimpreso de la Antologia del centenatio, vol. I, pp. (1)-ccxlv. BC-UC. 
347. — La vida literaria de México-Madrid, (Imp. Sáez Hermanos), 1917. 298-(3) pp. BC-BB-EM-UC-Y. (Lizardi, Rodríguez Galván, Altamirano, Gutiérrez Nájera, Cuéllar).

348. Unueta, Jesús, Conferencias y discursos literarios. Selección del autor--México, Edit. Cultura, 1920. 160 pp. (Altamirano, Sierra O'Reilly) BC-BU-Y.

349. Valadez, Edmundo, Atisbando a Facundo-Letras de México, 15 (15 sept. 1937), 6. EM.

350. Valdés Acosta, José María, $A$ través de las centurias...-Mérida, Yucatán, Talleres "Pluma y Lápiz", 1923-1926. 2 vols. ilustr. (Peón y Contreras) BN.

351. VALVERDE TÉllez, EMETERIO, Bibliografía filosófica mexicana. Segunda edición, notablemente aumentada. León, Imp. de Jesús Rodríguez, 1913. 2 vols. (Roa Bárcena, Juan N. Cordero, Flores Alatorre, Antonio Moreno, Pacheco, P. Parra, Pesado, Sosa y Alvila) BN-BC-UC.

352. Valle, Rafael H., Bibliografia de Manuel (sic) Ignacio Altamirano.-México, D.A.P.P., 1939 (al fin: Impreso en México, Talleres Gráficos de la Nación). 155 pp. BN-EM.

353. Valle-Arizpe, Artemio de, La gran Cibdad de México Tenustitlan...-México, Tip. Murguía, 1918. 119 pp. Cultura, t. 8, núm. 2. (Ramírez Áparicio). BN.

354. - La muy noble y leal cindad de México...-México, Edit. "Cultura", 1924. 336-(2) pp. (J. M. Marroquí) BN-BC-UC.

35s. Vargas, Gracia María, El cuento y la novela corta en México en algunos escritores del siglo XIX.-Tesis de maestra, Universidad Nacional Autónoma de México. México, D. F., 1937. 123-(1) pp. BC-BU.

356. VázQuez Santa AnNa, Higrnio, Bosquejos biográficos de bombres. ilustres nacionales.-México, Sec. de Gobernación, Dirección de Talleres Gráficos, 1920. 213-(2) pp. BC-EM.

357. Velízquez, José DE, Don Rafael Delgado.-Revista de Revistas, XIV, 697 (1923), 36. BC-NY-UT.

358. Velázquez Bringas, Esperanza y Valie, Rafael H., Indice de escritores.-México, Herrero Hermanos Sucs., 1928. 320 Pp. (Rabasa, Vigil y Robles) BC-BN-HS-EM-NY.

359. VigL, José María, Antologia de poetas mexicanos.-México, 1894. (Bramón).

360. - (Reseña bistórica de la literatura mexicana).-México, s.p.i. (¿1908?). 240 pp. Forma parte de una colección de sus obras truncas. (Bramón). BN.

361. Vrramontes, Leonardo S., Caltsas de nuestra escasa producción literaria y medios de combatirlas. Estudio presentado en los Juegos Florales de 1a Escuela de Jurisprudencia. México, Eduardo Dublán, Imp. 1902. 29 pp. BN. 
362. - La novela en México y el realismo en el arte. A través de Reconquista, último libro del Sr. D. Federico Gamboa. México, A. Carranza e hijos, 1909. 74 pp. UT.

363. WALKER, N., The life and works of M. Gutiérrez Nájera.-University of Missouri Studies, II, 2 (1927), 83 pp. Columbia; Missouri, 1927. BC.

364. WARNER, RALPH E., A recently discovered first edition.-Hispanic Review (Philadelphia, Pennsylvania), I (1933), 244-245. (Rimas: Altamirino).

365. - The life and work of Ignacio Manuel Altamirano.-Tesis de doctor en filosofia, Universidad de California. Los Angeles, California, 1935.

366. WeIrINGER, N. L., Readings from Spanish American anthors.Edited with biographical data and notes. Nueva York, Heath, 1929. vi, 265 pp. (Gutiérrez Nájera, Peza) BC.

367. WHEELER, HowARD T., The Mexican novel as a reflection of the national problems of Mexico.-Tesis de doctor en filosofía, Universidad de Stanford. Stanford, California, 1937.

368. WIIDENTHALL, MARY L., The expression of modernism in the Revista Azal. - Tesis de maestra, Universidad de Texas. Austin, Texas, 1937. (Angel de Campo y otros).

369. Wilkins, L. A., ed., Antologia de cuentos americanos.-Edited with exercises... with a critical introduction by Federico de Onís. Nueva York, Heath, 1924. xxiii, 286 pp. (Delgado, Riva Palacio) BC-EM.

370. WiLson, Irma, Mexico, a century of educational thought.-Tesis de doctor en filosofía, 1939. Universidad de Columbia. Nueva York, 1939.

371. Winter, C. J., Los bandidos de Río Frío by Manuel Payno.Books Abroad (Norman, Oklahoma), 3 (1929), 47.

372. WoolsEY, A. W., The novels of Federico Gamboa.-Tesis de maestro, Universidad de Texas. Austin, Texas.

373. W'RugHt DE Kleinhans, LaUREANa, Mujeres notables mexicanas.México, Tip. Económica, 1910. 546 pp. láms. retrs. (Barragán de Toscano) BN-BC-NY.

374. YANCEY, MURA L., Literary biograpbies of nineteenth century Mexico.-Tesis de doctor en filosofía, Universidad : de Colorado. Boulder, Colorado, 1939.

375. ZorrmLa, José, Literatura y arte. La flor de los recuerdos, ofrenda que hace a los pueblos bispanoamericanos.-México, Imp. del Correo de España, 1855. 2 vols. En el t. I. (Castillo, Díaz Covarrubias y otros) $B N$. 


\section{ADICIONES}

376. DownING, Todn, The bandits of Río Frio.-Mexican Life, XVI, 5 (mayo 1940), 15 et passim. (Payno).

377. Finlex, Theodore R., Ignacio Manuel Altamirano as interpreter of traditional Mexican life and customs.-Tesis de maestro, Universidad de Columbia. Nueva York, 1938.

378. Hamidton, Lucía F., Indications in the works of Manuel Gutiérrez Najera of bis reading in foreign literatures.-Tesis de maestra, Universidad de Iowa. Iowa City, lowa, 1938.

379. Gómez de Baños, VIRGINIa, Manucl Gutiérrez Nájera.-Tesis doctoral, Radcliffe College. Cambridge, Massachusetts, 1938.

380. Moore, ERNEst R., Studies in the Mexican novel.-Tesis doctoral, Universidad de Cornell. Ithaca, Nueva York, 1940. 420 pp. más 24 de bibliog. (Orígenes de la novela mexicana, Fernández de Lizardi, novelistas y movimientos principales del siglo XIX, novelistas de la revolución).

\section{N D I C E}

Nota.-No ha sido posible poner en lista todos los novelistas citados en cada obra biografica o critica. Por eso además de buscar un autor bajo su nombre hay que consultar las obras registradas bajo Blografras y Estudion Iterarios.

Agüeros, Victoriano, 8.

Alfaro, Anselmo, 221.

Almazán, Pascual, 247, 272, 332.

Altamirano, Ignacio Manuel, 38, 49, 85, 100, 121, 131, 132, 140, 144, $148,156,165,166,178,196,221,226,251,252,253,269,272$, $277,342,347,348,352,364,365,377$.

Ancona, Eligio, 234, 272.

Anónimos, Jicoténcal, 272, El misterioso, 272.

Arriaga, Alberto F., 236.

Barragán de Toscano, Refugio, 152, 373.

Betanzo, Francisca, (Chanteclair), 86.

Biografías, $22,30,37,40,41,42,43,73,74,88,89,108,113,114$, $122,177,179,219,220,222,226,227,228,243,258,299,304$, $311,312,356,374$.

Bolaños, Joaquín de, 25, 61, 62, 106, 314.

Bramón, Francisco, 61, 62, 257, 359, 360.

Bravo, Bernabé, 91.

Campo, Angel de (Micrós), 108, 165, 166, 192, 193, 194, 195, 261, $\therefore 368$. 
Carpio, Manuel, 28, 32, 77, 78, 112, 158, 203, 213, 254, 278, 306, 309. Castera, Pedro, 92.

Castillo, Florencio M. del, 15, 16, 23, 24, 112, 257, 275, 306, 309, 375.

Castillo, Rafael del, 287.

Ceballos, Ciro B., 119, 288.

Cordero, Juan N., 351 .

Couto Castillo, José Bernardo, 332.

Cuéllar, José Tomás de; (Facundo), 18, 21, 23, 24, 94, 104, 159, 165, $166,179,235,241,242,245,310,330,347,349$.

Chavero, Alfredo, 12, 23, 24, 56, 83, 118, 180, 235, 276, 300, 310, $329,332$.

Delgado, Rafael, 26, 27, 45, 92, 94, 108, 149, 153, 165, 166, 189, 213, $229,238,239,240,270,284,288,289,293,329,357,369$.

Diaz Covarrubias, Juan, 23, 24, 28, 112, 208, 254, 257, 272, 281, 283, $306,309,310,322,375$.

Díaz Dufóo, Carlos, 288.

Echäiz, Jesús, 335.

Esteva, Adalberto A., 92, 97, 292.

Estudios literarios, 3, 4, 8, 13, 17, 22, 23, 24, 30, 31, 33, 35, 36, 37, $38,39,43,47,48,54,58,59,60,61,62,63,64,65,67,68,69$, $70,73,74,75,76,81,82,103,108,109,110,124,125,130,133$, $136,137,143,146,150,151,157,160,162,163,166,167,168$, $169,170,172,187,188,190,198,200,202,204,205,206,207$, $212,214,215,216,217,219,220,225,231,249,251,252,253$, $255,256,258,260,266,267,268,272,284,285,286,291,293$, $294,296,297,298,303,305,315,325,327,338,339,340,343$, $345,346,355,361,367,368,370,375,380$.

Fernández de Lizardi, José Joaquín, (El Pensador Mexicano), 23, 24, $50,71,72,94,108,117,128,129,139,142,153,165,166,173$; $185,211,218,262,263,264,265,271,280,316,317,318,319$, $320,321,323,326,328,337,347$.

Ferrel, José, 116.

Flores Alatorre, Francisco, 2, 221, 351.

Frías, Heriberto, 44, 141, 190, 272.

Frías, Valentín F., (Alter), 44, 180, 332.

Frias y Soto, Hilarión, 23, 24.

Gallardo, Aurelio Luis, 112, 221, 254, 306, 309.

Gamboa, Federico, 135, 199, 209, 210, 285, 288, 302, 341, 362, 372.

García, Genaro, 44, 180, 332.

Gómez Vergara, Joaquín, 221.

González de Sancha, José, 61, 62.

González Sánchez, José, 257.

Guadalajara, José Rafael, 44.

Gutiérrez N̦ájera, Manuel, 12, 28, 66, 91,92, 98, 165, 166, 223, 224, $242,344,347,363,366,378,379$. 
Inclán, Luis G., 94, 131, 138, 218.

Iza, Luis G., 97.

Jens, Federico Carlos, 92.

López-Portillo y Rojas, José, 28, 44, 51, 52, 53, 57, 95, 102, 108, 154, $189,251,252,261,288,302,329$.

Martínez de Castro, Manuel, 272.

- Martínez Gracida, Manuel, 44, 236.

Marroqui, José María, 354.

Mateos, Juan A., 23, 24, 235, 272, 276.

Mejía, Demetrio, 182, 272.

Moreno, Antonio, 351.

Ochoa, Antonio de, 61, 62.

Ochoa y Acuña, Anastasio de, 11, 32, 61, 62, 72, 107, 112, 203, 230 , $254,306,309,333$.

Olaguíbel, Francisco $M$. de, 44, 105, 112, 115, 118, 180, 232, 233, $288,306,309,332$.

Olavarria y Ferrari, Enrique de, 19, 20, 250, 272.

Orozco y Berra, Fernando, 14, 23, 24, 112, 254, 257, 306, 309.

Ortiz, Luis G., 7, 19, 28, 221, 242, 310 .

Othón, Manuel José, 28, 50, 98, 112, 186, 223, 224, 259, 309, 333, 344.

Pacheco, J. R., 351.

Palma y Palma, Eulogio, 197.

Parra, Porfirio, 28, 92, 94, 118, 235, 329, 351.

Pavía, Lázaro, 44, 119, 197, 236.

Payno, Manuel, 23, 24, 94, 108, 134, 165, 166, 171, 235, 272, 276, $324,371,376$.

Paz, Arturo, 97, 116, 234.

Paz, Ireneo, 10, 44, 91, 97, 118, 272, 329.

Peón y Contreras, José, 1, 5, 6, 28, 34, 56, 155, 221, 276, 295, 306, $310,329,344,350$.

Pesado, José Joaquín, 32, 112, 145, 203, 254, 278, 306, 309, 333, 336, 351 .

Peza, Juan de Dios, 12, 28, 92, 118, 164, 221, 276, 282, 344, 366.

Piña Izquierdo, Juan, 257.

Pizarro, Nicolís, 23, 24.

Quevedo y Zubieta, Salvador, 44, 119.

Rabasa, Emilio, (Sancho Polo), 96, 108, 120, 123, 165, 166, 261, 290, $329,358$.

Ramírez, José Maria, 7, 23, 24, 99, 235, 310.

Ramírez Aparicio, Manuel, 353.

Ramírez Cabañas, Joaquín, 44, 119, 332.

Reynel Hernández, Marcos, (Fray Miguel de Santa María), 61, 62, 112, $306,309$.

Ríos, Juan Pablo de los, 91. 
Riva Palacio, Vicente, $20,23,24,28,87,93,101,104,164,165,166$, $180,221,235,261,272,282,283,301,308,332,369$.

Rivera y Río, José, 23, 24.

Roa Bárcena, José María, 6, 28, 112, 147, 165, 166, 273, 276, 292, $309,329,351$.

Rodríguez Galván, Ignacio, 23, 24, 32, 33, 112, 120, 158, 203, 248, $254,306,309,333,336,347$.

Rodríguez Rivera, Ramón, 92, 235.

Rosas Moreno, José, 28, 50, 112, 174, 203, 221, 244, 254, 306, 309.

Ross, María Luisa, 44, 119.

Rubín, Luis G., 44.

Ruiz, Eduardo, 79, 118, 161, 234, 235.

Sánchez Mármol, Manuel, 236, 237, 300, 307, 329.

Sierra O'Reilly, Justo, 1, 18, 55, 79, 80, 112, 170, 175, 176, 201, 246, $257,272,276,283,306,309,313,331,348$.

Sierra, Justo, (Hijo), 28, 38, 46, 56, 90, 98, 111, 118, 126, 127, 153, $165,166,170,221,274,279,310,329,344$.

Sigüenza y Góngora, Carlos, 183, 184.

Silva, Agapito, 7, 92, 97, 181, 221, 310, 335 .

Sosa, Francisco, 28, 44, 97, 99, 235, 250, 276, 329.

Sosa y Avila, Francisco, 351.

Sotomayor, José Francisco, 334.

Tovar, Pantaleón, 16, 23, 24, 84, 112, 254, 257, 306, 309.

Valle, Ramón, 2, 50, 174.

Vigil y Robles, Guillermo, 44, 358.

Villaseñor, Pablo J., 254, 332.

Villaseñor y Villaseñor, Alejandro, 29, 197, 329.

Villaurrutia, Jacobo de, 9, 61, 62, 257.

Zárate, Eduardo E., 118, 221, 236, 292.

Zayas Enriquez, Rafael de, 23, 24, 92.

ERNEST R. MOORE, Universidad de North Carolina,

(1).-Esta bibliografía ha sido compilada con la ayuda de una beca que recibio el autor del American Council of Learned Societies. 